\title{
Training and Development for Radiographers' Extended Roles: a case of ad hoc implementation?
}

\section{Short title: Training for radiographers' extended roles}

\section{Authors:}

Linda Miller, BSc, PhD, Institute for Employment Studies

Richard Price, FCR, MSc, PhD, School of Health and Emergency Services, University of Hertfordshire

Martin Vosper, BSc, HDCR, PgDip, MSc, School of Health and Emergency Services, University of Hertfordshire

Address for correspondence

Dr Linda Miller

The Institute for Employment Studies

Sovereign House

Church Street

Brighton

BN1 1UJ

Telephone: 01273763400 Direct Line: 02074706137

E-mail: linda.miller@employment-studies.ac.uk

\section{Acknowledgements}

This research was funded by Skills for Health. The authors would like to thank Kathryn Halford and Robert Standfield for their support. We would also like to thank all those managers who responded to the survey and participated in the interviews. 


\section{Training and Development for Radiographers' Extended Roles: a case of ad hoc implementation?}

\section{Abstract}

This paper examines the quality and consistency of post-registration training and development for extended role activities undertaken by radiographers. Although the undergraduate curriculum has changed to some extent to accommodate expanded role requirements, much of the training does not, and cannot, take place until radiographers are qualified and in post. While undergraduate programmes in radiography must be approved by the Health Professions Council, and are normally accredited by the radiographers' professional body, the Society and College of Radiographers, much of the training provided for extended role activities is ad hoc and neither validated nor accredited. This paper reports the outcomes of a survey of imaging service managers and follow-up interviews with imaging service managers. Managers' views of the quality of training and development provided for extended role activities and their approaches to recruiting radiographers with extended role experience were explored. The research identified concerns amongst managers regarding the training currently available and indicated potential career disadvantages for radiographers receiving unaccredited development. There is also some evidence of wastage arising from 
the duplication of training by Trusts because of uncertainty about the standards of competence instilled by programmes.

Key words/phrases: Radiographers; extended roles; competence; training and development; career progression, external standards. 


\section{Training and Development for Radiographers' \\ Extended Roles in the United Kingdom: a case of ad hoc implementation?}

\section{Introduction}

Progress in imaging technology has increased the demands placed on radiologists and radiographers. Figures from the Department of Health (2009) reveal an overall increase of 22 per cent in imaging activities from 1995 to 2008. Increases in X-ray examinations have constituted a relatively small part of this overall increase; most growth has been seen in other imaging modalities: MRI (147 per cent increase), ultrasound (47 per cent), the use of radioisotopes (25 per cent) and CT (17 per cent) (Department of Health, 2004).

Growth in the numbers of radiologists has failed to keep pace with the widening range of imaging modality options and increasing demand for imaging services. It is unsurprising therefore that other means have been sought by which to expand the service. Barneveld Binkhausen (1992) was the first to predict that expansion of imaging technology would impact on radiographer roles and lead to extension of their activities into areas historically the responsibility of radiologists. In the UK, the North East Thames Regional Health Authority used activity sampling to provide a 'snapshot' of radiographer roles, with their subsequent report recommending expansion of radiographers' involvement in image evaluation in particular (North East Thames Regional Health Authority, 1993); by 
1995, Paterson had found increasing numbers of examples of overlaps between the roles of radiologists and radiographers; and in 1995 the Audit Commission called for 'radical rethinking' of the way in which technological and clinical innovations in radiological services were handled.

Subsequent research indicated that imaging service managers, radiologists and the companies involved in developing imaging technologies all believed that further changes in technology will inevitably drive up the demand for more - and different - skills amongst radiographers (Price, Miller and Payne, 2000). Price, Miller and Mellor, (2002) reported on patterns of adoption of extended role activities. Figure 1 summarises the results from two surveys undertaken in 1998 and 2000, and indicates the extent to which extended role activities have been introduced in NHS trusts across the UK over the past 20 years.

\section{PLACE FIGURE 1 ABOUT HERE}

The data suggest that some radiographer extended role activities, such as intravenous injections, ultrasound reporting, barium enemas and 'red dot' schemes are now regarded as standard practice, being undertaken by radiographers at almost all NHS acute trusts. However, the results also showed that, although widespread, implementation of extended roles still remained ad hoc, rather than planned at either Trust or SHA level, or indeed, through the Department of Health. 
More recent work undertaken for the Society and College of Radiographers (SCoR) provided a further update on the scope of radiography practice (Price et al. 2008). The research identified and quantified the different healthcare environments in which the radiography workforce operates, along with the individual roles and areas of specialisation currently in place, and indicated firstly, that radiographers are involved in an increasingly diverse range of activities in a wide range of settings, and secondly, that this was driving demand for more radiographers to take on expanded role activities. Activities such as intravenous injections and audit are now undertaken by radiographers in more than 90 per cent of hospitals, while radiographers led on intravenous urography and computed tomography (CT) examinations in over 80 per cent of hospitals. There are also increases in "hot reporting" and magnetic resonance imaging lead roles.

\section{Training for extended role activities}

In 1997 Price, High and Miller reported on work commissioned by the (then) College of Radiographers and The Radiographers' Board to examine the extent to which the introduction of new imaging technologies was bringing about changes in the demands made of radiographers and the implications of such changes for education and training at both undergraduate and post-graduate (or, for those who qualified before introduction of the degree programmes, post-registration) levels (Price, High and Miller, 1997). There was agreement amongst the imaging managers interviewed at that time that the majority of extended role activities should remain the province of post-registration development, rather than become part of the undergraduate curriculum. While some extended role 
activities have begun to appear within degree programmes much of the training for extended roles continues to be largely provided as post-registration development.

Data gathered by Price during the 2000 survey $^{1}$ on the types of training and development provided for radiographers involved in extended role activities revealed a very broad range of approaches (Price, 2006). For example, the duration of training to prepare radiographers for administration of intravenous injections ranged from half a day to six months and for administration of barium enemas, from just one day to twelve months. Of equal concern was the discovery that, in a high proportion of cases, the training was not conducted to any externally-determined standard or validated by an external body. Nearly one-fifth of barium enema training was non-accredited. Over half of intravenous injection training was non-accredited.

Such variations in practice must necessarily lead to questions regarding the equivalence of the competence levels developed by the training provided at different trusts. There are several reasons for concern. Principal amongst these must be the potential implications for patient safety, but in addition the situation is unsatisfactory from the point of view of both employees and employers. For employees there are questions regarding the 'transferability' of any training and skills where qualifications are not benchmarked or accredited. For employers, the lack of accreditation brings potential problems for recruitment and selection: should a job applicant who has been through an internal,

1 This data was collected as part of the survey that was reported in Price et al. (2002) but not reported in that article. 
unaccredited, training programme provided by their previous employer be considered eligible for a post requiring competence in extended role activities, and, if appointed, be assumed to be fully competent to undertake such tasks? If a competent individual is recruited who has experience but no accredited proof of training, then there is the risk that imaging managers will feel they have to re-train recruits (and, potentially, duplicate training) where the standard of training provided previously cannot be confirmed. Such duplication in turn brings cost implications for Trusts.

\section{The research}

Given the reactive nature of many current developments in relation to radiographers' extended roles, it was of interest to discover the range and quality of training and development in place to support them. In 2008 Skills for Health agreed to fund research to enable a current assessment of training provision and compare this to the situation that pertained in 2000 (reported in Price, 2006). The aims of the study were to:

- profile the extent and nature of training and development provided across the UK for 'extended role' activities undertaken by diagnostic radiographers and the extent to which provision is mapped against external standards and/or accredited by external bodies.

- explore hospital policies relating to the recruitment of individuals with accredited and non-accredited training for extended role activities.

The study received approval from the Institute for Employment Studies' Ethics Committee in May 2008. 


\section{Methodology}

Diagnostic imaging managers in all major NHS trusts across the United Kingdom were surveyed using a postal questionnaire mailed out with a covering letter in June 2008. The questionnaire asked about the types of extended role activities undertaken by radiographers in their department, and the nature of the training provided for these activities. The questionnaire also sought additional information on managers' views of the adequacy of training available for radiographers' extended role activities; whether managers typically asked for extended role experience when recruiting staff and, if so, what their policy was regarding prior training and qualification for those activities; managers' experience of recruiting staff with experience in extended role activities, and quality and consistency of training for extended role tasks. Respondents who were willing to take part in a later telephone interview were asked to provide contact details. Those who did not volunteer for interview were not asked for any details that could identify them.

Those who volunteered to be interviewed and raised concerns about issues such as the availability of training or the nature of training available were contacted and a telephone interview was conducted. Interviews explored the concerns managers had regarding training that had been provided for their existing staff or had been received in the past by newly-recruited staff. Their views were also sought on recruitment policy and areas of skills shortage in extended role activities. The telephone interviews were undertaken during September and October 2008. 


\section{Results}

A total of 48 questionnaires were returned, giving a response rate of 17.6 per cent. Some 45.8 per cent of returns came from teaching trusts, and 54.2 per cent from non-teaching trusts. Although returns were received from all health regions, the relatively small response rate may have reflected the length and complexity of the questionnaire. It may also reflect 'response fatigue', given that they had been contacted just a few months earlier in connection with the 'Scope of practice' research.

\section{Participation in extended role activities}

Reported extended role activities for radiographers are displayed in Table 1 . The table also permits comparison with previous data obtained from the Scope of Practice survey (conducted in 2007/early 2008 and reported in Price et al. (2008) and from the extended role survey conducted in 2000 and reported in Price et al. (2002).

\section{PLACE TABLE 1 ABOUT HERE}

Comparison with the 2008 SCoR dataset indicates that, while the current survey data are not perfectly aligned with the results of the earlier SCoR findings, there are no systematic differences either - in other words, the present data do not show any signs of systematic under- or over-reporting of extended roles. Therefore, although the survey response was lower than anticipated, the profile of responses appears to be reasonably representative of the profession as a whole. Looking across the three datasets, it can be seen that there has been an increase in the adoption of each of the eleven extended roles for which Price et al. (2002) previously reported data. The largest increase is for appendicular skeleton 
reporting, where the proportion of trusts reporting radiographer involvement in the activity has grown from a quarter of sites to nearly three-quarters.

\section{Training for extended role activities}

\section{Duration of training}

Table 2 provides an overview of the minimum and maximum lengths of training duration reported for the 20 extended role activities included in the survey.

\section{PLACE TABLE 2 ABOUT HERE}

The results indicate wide variations in both the duration and nature of training to equip radiographers to undertake extended roles. As might be expected, training for more complex roles tends to be of longer duration than that provided for less complex activities, although some variation or overlap is seen.

\section{Training providers}

Training for activities that have now become a routine extended role for the majority of radiographers (eg administering intravenous injections) was more likely to be provided 'in-house' than that for tasks which have been adopted more recently (eg undertaking barium enemas). Around two-fifths of departments provided internal training for radiographers involved in 'red dot' schemes, and a similar proportion sent radiographers to external training for this activity, with the remainder using a mix of external and inhouse training. More than half of the training for radiographer-led IVU was provided inhouse within imaging departments (60 per cent). The data relating specifically to image reporting activities (including axial and appendicular skeletal, chest, ultrasound, 
paediatric, mammography and barium enema reporting), revealed that the majority of training $(75-80 \%)$, was conducted externally, normally in universities.

\section{Approval and accreditation of training for extended role activities}

Respondents were asked to indicate whether the training provided for these activities was approved and/or accredited ${ }^{2}$. The data indicated that unapproved and unaccredited training was quite common for less complex activities such as administering intravenous injections but training for more demanding tasks was more likely to be approved and/or accredited. Table 3 provides an illustrative comparison between IV training and barium enema training.

\section{PLACE TABLE 3 ABOUT HERE}

The analyses also revealed that over half (55.6 per cent) of the training provided for 'red dot' schemes and nearly half of the training for radiographer-led IVU (44.4 per cent) is currently not approved or accredited. In contrast, only a small proportion of training provided in ultrasound reporting (9.4 per cent) was not approved or accredited.

The extent of approval or accreditation of training does not appear to correlate with the invasiveness of, or risks associated with, the clinical procedure. Catheter insertion carries a number of potential complications and CT delivers the highest proportional dose from ionising radiation, yet training in both of these areas appears to be largely non-accredited.

2 It should be noted that a glossary of these terms was provided on the front page of the questionnaire. 


\section{The incorporation of extended roles into radiographer posts}

Extended role experience is now widely requested in job advertisements for radiographers. Nearly two-thirds of respondents (58.3 per cent; 28 respondents) indicated that they asked for extended role experience when advertising for staff. This is mostly for recruits at bands 6 and above. Just over a fifth of the respondent sample as a whole (22.9 per cent), and 44 per cent of those who said that they requested extended role experience when advertising, said that they required extended role experience at band 6 .

\section{Recruitment to posts requiring extended role responsibilities}

Respondents were asked if they would shortlist applicants with non-externally accredited training when recruiting staff. Typically organisations preferred to recruit individuals who had received accredited training. Of the 47 respondents who answered this question, 41 (87.2 per cent) said they would shortlist externally-accredited candidates, while another six (12.8 per cent) said that it would depend on the accrediting body. Fewer, 36 (76.6 per cent) said they would shortlist applicants with non-externally-accredited training for extended role activities and 9 (19.2 per cent) said they would not. Probably as a result of this, managers were significantly less likely to have recruited individuals with unaccredited training than those with accredited training $\left(\chi^{2}=16.1, \mathrm{df}=1, \mathrm{p}<0.001\right)$ (see Table 4).

\section{PLACE TABLE 4 ABOUT HERE}

\section{Quality and consistency of training for extended role activities}

Diagnostic imaging managers were asked about the training for extended role activities that they themselves had commissioned. Although the great majority (over 95 per cent) of 
such managers said that they had been satisfied with the standard of training provided and the level of competence attained by their staff, just under half also said that they did not believe that all radiographers were currently being trained to the same competence level in extended role activities.

\section{Managers' confidence in the prior training of recruits}

Those managers who had recruited radiographers who had been trained in extended role tasks while in a previous job were asked about their confidence in the standard of training previously received by that/those individuals. Where managers had recruited radiographers with unaccredited training they were significantly more likely to have lacked confidence in the standard of their recruits' training than were those who recruited individuals who had received accredited training $\left(\chi^{2}=10.2 . \mathrm{df}=2, \mathrm{p}=0.006\right)$. The responses are presented in table 5 .

\section{PLACE TABLE 5 ABOUT HERE}

\section{Remedying perceived deficiencies in prior training}

Those managers who reported having lacked confidence in the prior training in extended role activities received by recruits were asked if they had provided any additional training for those individuals following their recruitment. A total of seventeen had done so; of these, more had provided remedial training for recruits whose prior training had been unaccredited (13 out of 16$)$ than had done so for recruits with accredited training (4 out of 7).

Respondents were asked if they believed there was a need for external standards to be developed to provide benchmarks for competence in extended role activities. Perhaps 
unsurprisingly, given the above, there was a clear majority in favour of external standards for performance in these activities (85.4 per cent). The majority of respondents (87.5 per cent) also believed that there was a role for a validating/professional body to play in validating or endorsing training for extended role activities.

\section{Recruiting, selecting and employing staff with extended role experience}

The survey allowed respondents to give free text comments in response to the questions about quality and consistency of training and development. In addition, a selection of managers was interviewed by phone, in order to explore the issues that had been raised by respondents in their survey returns. The outcomes of the interviews with radiography managers, together with the free response comments made in the questionnaire survey are reported in the following sections.

\section{Procedures for recruiting and selecting staff with extended role experience}

The survey indicated that just under half of managers had sought to recruit staff with extended role experience. While many had previously developed these skills in their staff through provision of in-house development, fewer had experience of attempting to recruit staff with extended role experience.

‘We have only just put out our first job ad where we have really asked for extended roles, previously it has all been in-house training, we have asked for plain film reporting.' 
Therefore, some managers were having to consider for the first time the recruitment and selection procedures they would need to use in selecting these individuals. It appeared that procedures had not been designed to assist in recruiting and selecting staff with extended role skills.

Managers typically wanted to seek information about applicant' post-registration experience, but most trusts used the standardised, online NHS application form, which was not viewed as helpful when recruiting staff with additional skills. While these forms allow individuals to provide additional relevant information, they did not allow managers to ask applicants for specific information relating to prior experience in extended roles.

It is a generic application form for all NHS jobs - porters, people who work in the kitchens, physio, they all fill out the same application form. It is not ideal. There is room on the form for you to put your experience, or training course, but it is really up to the individual, [there is] nothing that asks for specific information about skills.' Interview with radiographer manager

'I have to use the NHSnet form and it's poor. We can't control the content of the form.' Interview with radiographer manager

Managers were asked about any policy they might have relating to gaining further information about the training and qualifications attained for extended roles when interviewing applicants. While typically they asked applicants about their previous 
qualifications and training during selection interviews, there was no real protocol in place to ensure that trusts checked the status of that training:

'If someone said to me they'd been on an external course, you're saying, would we check it? I'd like to say we did, but if I was honest I'd probably have to say we probably don't. ..we tend to believe what people say. I guess we should ask for the certificate, but I think we don't'.

Interview with radiographer manager

\section{Deployment of new recruits with training in extended role activities}

The survey data had indicated that where recruits had not undertaken an accredited course this could lead to managers having to pay for duplicate training in order to ensure the individual was accredited for the work. The interviews therefore sought information on what happened once recruits started work. One manager gave a description of their policy that required anyone who had not undertaken accredited training to attend college to ensure patient safety:

'If someone came in with experience of IV injecting but hasn't actually done the college course, we would actually send them to college....we want to make sure everybody is the same level and confident. And it's for their protection really and for that of the patients. And it is a difficult situation where you've got somebody saying they've been injecting from when radiographers first started injecting and they haven't done the course and you say to them 'Well you have to go back to college' and it is a difficult situation..' 
However, the same manager also acknowledged that there were some radiographers in his department who were in the same situation as the newer recruits.

'Of course I do have people here who have done injecting for years and years and who haven't done the college course, but it's perhaps a little late in their professional careers to send them off studying again, but anybody new, now, we will send them off on the college course.'

One of the main points of interest in conducting the research was to determine whether staff who were trained in-house were at any disadvantage in the labour market compared to those who undertake external, accredited, courses. The example given suggests that the policy introduced in order to avert any difficulties with new recruits could, ultimately, lead to existing staff being at a disadvantage compared to those newer recruits. Furthermore, this policy probably meant that if any of this trust's longer-serving radiographers moved to new posts in the future, then their new employer too would probably also require them to be re-trained.

The main focus of this part of the research had been on the situation of radiographers who had undergone non-accredited training. However, it emerged that, in one trust, any new recruit with training in extended role activities was required to undergo in-house training, even if the training was accredited. The trust had introduced the policy because of concerns that external courses might not deliver the competence levels they required: 
'We've had radiographers who've turned up with Society of Radiographers certificates in cannulation but we don't let them [do it]. If they want to cannulate they have to go through the course in cannulation, as that's a trust policy.

Interviewer: So you would always routinely re-train?

Yes. It's because it's one of those areas where you get a wide group of staff come in claiming to have these skills, an international range [of staff]....so the Training Department just put the blanket ban down, they said no, if you want to do it, you have to do the training and then get the competencies signed off. And that includes UK institutions as well.'

Interview with radiographer manager

It is perhaps not surprising that some trusts are adopting this approach, given that the survey had revealed that over half of managers believed there was variation in the training provided for extended role activities:

'Having had staff attend courses at different universities, the standard achieved on completion is varied and the experience gained [is also] varied.' Survey response

'As the number of training providers increases we need assurance.' Survey response

While managers were generally happy about the standard of the post-registration training that they themselves had commissioned, in some cases they felt that there had been a lack of clarity about the course content, or the additional work and/or support that would be needed before the trainee could be considered to be fully competent. Sometimes the 
ambiguity appeared to be part of a deliberate attempt to attract more trainees onto the course:

'It was insufficient. In my naivety I looked at it and I thought "that will be alright", but if I did the same thing now I would be looking in a lot greater depth at all of these things, I would be more suspicious .... at the time I should have known that that was the terminology being used, but then again I was certainly led up the garden path by the lady I spoke to there, she put a spin on it. She said it could be used for reporting. She could have said something like "it can be used as a basis for reporting but you will have to do a lot more".'

Interview with radiographer manager

In this particular case the manager felt that a misleading account had been given regarding what the course would equip his radiographers to do. In other cases, though, managers found that it could be difficult to judge the applicability and appropriateness of training:

'Training is sometimes a bit piecemeal. There are different courses and it's hard to compare them. Their applicability can be different. Academic ratings like credits can be confusing. There's a difficulty in working out the parity between courses and between credit ratings. I need more information. There should be more open information on course content.'

Interview with radiography manager 


\section{Ensuring the competence and safety of recruits with prior training}

The research revealed that some managers have had concerns in the past about the standard of training received by recruits and one trust had addressed this problem by insisting that all staff who wanted to undertake work in areas outside current preregistration training were required to undergo in-house training. Another did the reverse, requiring new recruits to undertake an accredited college course. In both cases, this involved paying for what is, in many respects, duplicate training. However, one manager gave an account of a more economical approach which had allowed managers to have their experienced staff assessed by a university to confirm that they had met required standards:

'I worked in a trust and I'd been injecting [patients] for a long while and the manager there [decided] 'Oh well I think we should have some accreditation', and [he] arranged for the course provider to come in and [assess] about half a dozen of us who were all in the same situation, so we didn't have to go to college, they came in and signed us off and gave us a quick refresher, but I think the college has stopped doing that now. Which is a shame because it certainly worked well for that group of people.'

Interview with radiography manager

One of the issues explored in the interviews was the question of whether some type of external standards should be developed to serve as a national benchmark. These would provide a performance standard against which both experienced or staff going through training could be assessed. One manager felt that there would be a further benefit to this 
approach: national standards would also help managers to maintain service quality over time:

'A lot of the role extension takes place in smaller departments. So if someone undertakes a procedure, like a large radiographer-led DG service, then it's important that there are some things you can link it to, to create some standards for the staff you've got. So there's some national competency. People do a qualification in plain film reporting but what happens afterwards? What happens year-on-year to allow you to ensure you have excellent practice?'

Interview with radiography manager

Another questioned whether, where radiographers are trained through courses run inhouse, radiographers developed fully transferable skills. The interviewee was asked whether, if external standards were available, they might consider benchmarking their inhouse courses, and whether this might make life any easier for them.

'Oh yes, definitely... if there was a national standard to compare these things to then that would be very helpful to us as we could say this is what you would cover in your reporting course, or it would make it easy from a CPD point of view.'

Interview with radiography manager

Over eighty per cent of survey respondents had indicated that there would be some utility in developing external standards to use as benchmarks. Their comments included: 
'Using external benchmarks is the only way to ensure standards and make training truly transferable.' Survey response

'A gold standard of image reporting should be developed.' Survey response

\section{Is there a role for a validating/accrediting body?}

Survey respondents and interviewees were asked if there might be a role for a validating or accrediting body to play in validating training for extended role activities, and if so, who might fulfil this role. Over 80 per cent of respondents supported this idea, with either the College of Radiographers or the Health Professions Council being suggested as appropriate validating bodies. However, some predicted difficulties with such a scheme, while others believed this would bring more (unwelcome) bureaucracy:

'If an external body validated training there would have to be a charge. Who pays - the employer of staff? What's in it for the employer?' Survey response

'Accreditation for training may lead to more paperwork. There is currently too much paperwork in the NHS.' Survey response

Nonetheless, managers could see that accreditation could enable high-quality in-house training schemes to gain formal recognition and would encourage more local provision. This in turn would help to promote further role extension:

'The opportunities are there for radiographers to extend their role into advanced practice and we should be ready to support this with standardised accredited programmes to enable movement between trusts. Locally provided courses would probably benefit departments 
and enable advanced practice to become the normal pathway in the future.' Survey

response

Despite enthusiasm for extended roles and in general for accreditation of training by an external body, the majority of managers (57.4 per cent) did not feel that any more of the extended role activities should be included in pre-registration training, with less than a third (29.8 per cent) thinking they should. Given this view, it is likely there will be a requirement for CPD support for these activities for the foreseeable future.

\section{Discussion and Conclusions}

The survey confirmed that radiographer involvement in extended role activities had continued to increase since the last survey. In line with the findings of Price (2006), the provision of training for extended roles remains variable. Duration of training for some of these activities can vary from less than a day to two years. In general, more complex tasks receive longer training, but there is no real consistency. The survey also revealed that training for more complex tasks was more likely to be accredited and approved, but not always. Taking the administration of barium enemas as an example of a more complex activity, nearly ten per cent of training for this activity was unapproved and unaccredited. While this is a small proportion, it is sufficient nonetheless to raise concerns regarding quality of the training and, hence, patient safety. For simpler tasks - and here taking intravenous injections as an example - the figure for unapproved and unaccredited training rises to over 40 per cent. While administering injections is a (relatively) simple task, nonetheless it remains important that it is competently undertaken, and with 
training that is not subject to any type of external review or approval process there is the possibility of standards being lower than expected.

The majority of managers felt there was some need for external standards to serve as a benchmark for extended role training and for such training programmes to be validated and accredited by a professional body. Where trusts provide high quality internal training programmes for extended role activities, external benchmarking and accreditation would allow trusts to formally accredit such programmes and for individuals to acquire a recognised qualification.

\section{Recruiting and deploying staff with extended role experience}

One of the main reasons for accrediting training is to ensure patient safety by qualityassuring the level of training received by professionals. However, it is not just patients who potentially may suffer from training being unaccredited. A sizeable proportion of managers (18.8 per cent) reported that they would not shortlist a job applicant with unaccredited training for a post requiring some extended role responsibility. Fewer departments had recruited individuals with unaccredited training than had recruited individuals with accredited training. This is unsurprising given the finding regarding their shortlisting policies. 
Together, these findings indicate that a lack of external accreditation for training received can impact on individuals' career progression opportunities. In addition, too, there are clear cost implications arising from lack of confidence in existing training. A sizeable proportion of managers reported having provided additional remedial training for recruits. Far more reported doing so for recruits with unaccredited training than for those who had received accredited training. This suggests that significant sums of money are being spent duplicating training and lends some weight to the suggestion that on occasions unaccredited training may constitute a risk to patients. Some hospitals had adopted a policy of simply refusing to accept as adequate any training for extended role activities provided prior to recruitment and routinely re-trained all personnel prior to involvement in extended role activities. In one case all new recruits were sent for external training at a college; in another all new recruits were required to undertake re-training inhouse. The costs involved where such 'blanket' re-training policies are in place must be significant, although at present trusts clearly feel (probably rightly) that this is justified in order to ensure patient safety. The use of external standards either for benchmarking and the basis for accreditation of training programmes or as a means to assess individuals' current competence (rather than completely re-training) would provide a way in which to assure performance levels and reduce re-training costs.

\section{Ensuring competence}

The survey findings suggest that there is a great deal of support for standardisation and regulation of training for extended role activities. The occupational standards for diagnostic ultrasound developed ten years ago by the then College of Radiographers and 
Radiographers Board at the Council for Professions Supplementary to Medicine (Fernando et al., 2000; Prime et al., 2000) have been incorporated into departmental protocols in some departments to provide assurance of the ultrasound service, providing an exemplar of how occupational standards can be used.

More recently, further progress has been made: the Skills for Health Modernising AHP Careers programme has seen the development of occupational standards for some of the more frequent areas of extended practice: administration of intravenous injections and reporting ${ }^{3}$. These clearly would be appropriate for use in the ways identified by the manager who spoke of a scheme in which all staff had been assessed at work to ensure competence.

It is clear that, as well as providing a means to quality assure individuals' performance in these activities, standards for extended role activities, along with a recommended assessment regime, could form the basis for post-registration qualifications for radiographers engaged in extended role activities. Certification of standard levels of competence would render their skills more transferable and enable trusts to recruit staff with extended role experience with more confidence in future.

All medical doctors are required to undergo revalidation and relicensing from late 2009 onwards (DH, 2007). The Department of Health report on the regulation of non-medical 
professions (DH, 2006) suggests that relicensing arrangements may eventually be introduced for other professional groups too. This is likely to require evidence of continuing development, in addition to proof that performance has been maintained at or above the level set for entry to the profession. Regulating new professional roles as they emerge is likely to be one of the components of the process, and it is probable that this will encompass extended roles as well as newly emerging jobs. There are now two jobs ahead: to ensure that the development of occupational performance standards for extended roles keeps pace with the speed of role extension; and to raise awareness of and encourage use of the existing occupational standards by radiography managers.

\section{References}

Barneveld Binkhuysen, F H. (1992) Impact of PACS on radiologists' daily work in western countries. IEE Journal on Selected Areas in Communications 10: 7, 11581160.

Department of Health (2004) http://www.performance.doh.gov.uk/hospitalactivity/data_requests/download/imagin g and_radiodiagnostics/imag_ts.xls (accessed 5/11/04).

Department of Health (2006) Regulation of the non-medical healthcare professions. London: DH.

http://www.dh.gov.uk/en/Publicationsandstatistics/Publications/PublicationsPo licyAndGuidance/DH 4137239

Department of Health (2007) Trust, assurance and safety: The regulation of health professionals. Cm 7013. London: $\mathrm{DH}$ http://www.dh.gov.uk/en/Publicationsandstatistics/Publications/PublicationsPo licyAndGuidance/DH 065946

\footnotetext{
${ }^{3}$ See https://tools.skillsforhealth.org.uk/careerframework/show/view/comps/id/17
} 
Department of Health (2009) Imaging and radiodiagnostic activity, 2008/09.

http://www.dh.gov.uk/en/Publicationsandstatistics/Publications/PublicationsSt atistics/DH_103389

Fernando, R, Prime, N., Miller, L. and Mitchell, L (2000) 'The development of occupational standards in the practice of diagnostic ultrasound: Part 1, Background'. Radiography, 5, pp. 215 - 220

North East Thames Regional Health Authority (1993) Imaging Department Skill Mix Study. London: NTHRHA.

Paterson, A (1995) Role Development - Towards 2000. a survey of role developments in Radiography. London: The College of Radiographers

Price R, Miller L and Payne G (2000), 'Re-engineering the Soft Machine: the impact of developing technology and changing practice on radiographer skill requirements'. Health Service Management Research, 13, pp. 27 -39

Price $\mathrm{R}$ (2006), Developing practice in radiography and diagnostic imaging. PhD, University of Hertfordshire

Price R, Miller L and Mellor F (2002) 'A longitudinal survey of extended roles in radiography' Radiography 8, pp. $223-234$.

Price R, Vosper M, Heasman F, Edwards H, Miller L, LeMasurier S, Herbland A, Todd A (2008) Scope of Radiographic Practice. Hertfordshire: UH

Prime, N., Fernando, R, Miller, L. and Mitchell, L (2000) 'The development of occupational standards in the practice of diagnostic ultrasound: Part 2, the process and the outcomes'. Radiography, 6, pp. $43-50$ 


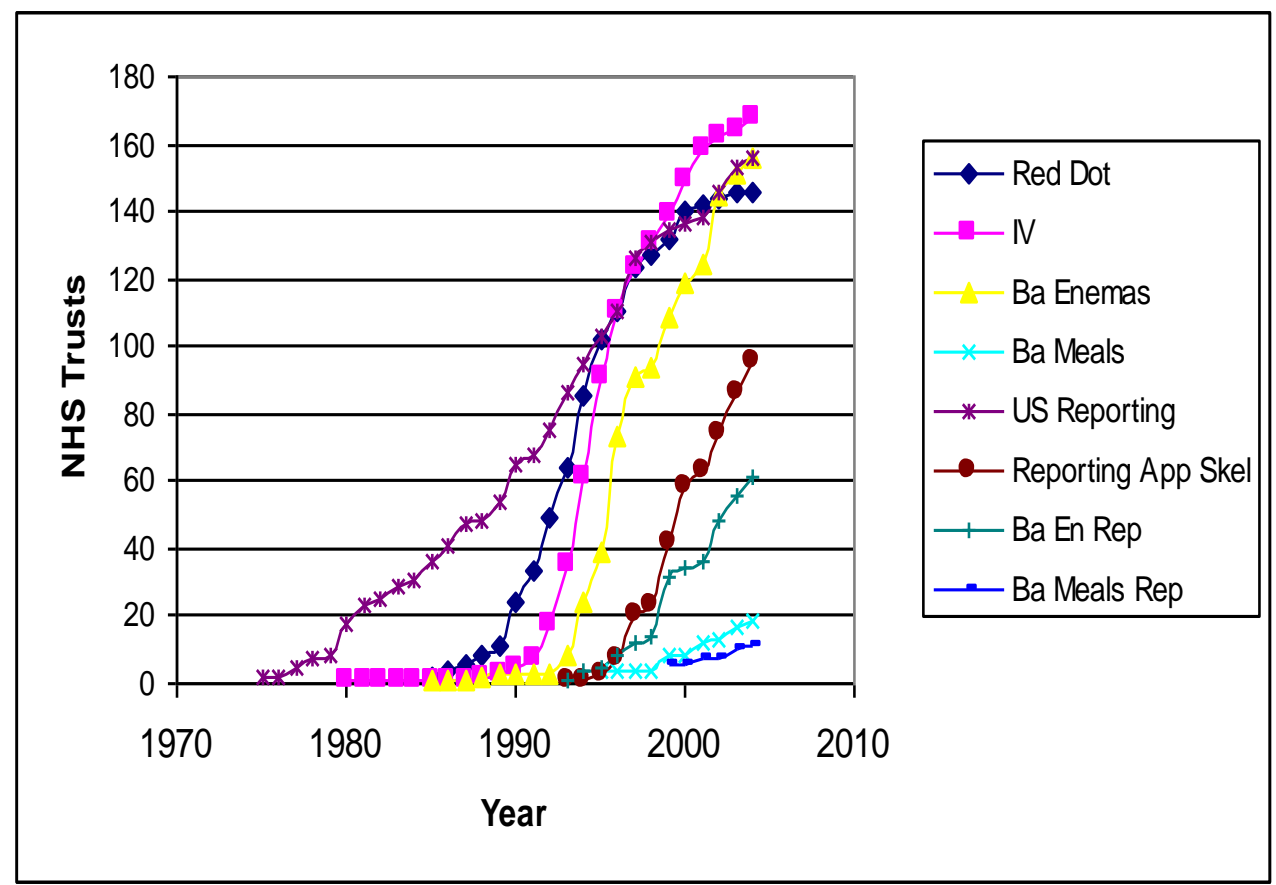

Figure 1: Adoption and diffusion of extended roles in the UK (cumulative) 
Table 1: Participation in extended role activities

\begin{tabular}{|c|c|c|c|c|}
\hline & $\begin{array}{l}\text { Count } \\
N=48\end{array}$ & $\begin{array}{c}\begin{array}{c}\text { Percentage } \\
\text { participation }\end{array} \\
2008\end{array}$ & $\begin{array}{l}\text { Percentage } \\
\text { participation, } \\
\text { Price et al. SCoR } \\
\text { data (2008) } \\
\text { (data collected } \\
\text { in 2007/08) }\end{array}$ & $\begin{array}{l}\text { Percentage } \\
\text { participation, } \\
\text { Price et al. } \\
(2002) \\
\\
\text { (data collected } \\
\text { in 2000) }\end{array}$ \\
\hline Intravenous injections & 48 & 100.0 & 94.4 & 95.0 \\
\hline Ultrasound reporting & 46 & 95.8 & - & 72.1 \\
\hline Conducting barium enemas & 41 & 85.4 & - & 69.0 \\
\hline 'Red dot' scheme & 39 & 81.3 & 93.5 & 82.0 \\
\hline $\begin{array}{l}\text { Appendicular skeleton } \\
\text { reporting }\end{array}$ & 35 & 72.9 & - & 25.0 \\
\hline Axial skeleton reporting & 24 & 50.0 & - & 11.6 \\
\hline Barium enema reporting & 24 & 50.0 & - & 19.8 \\
\hline $\begin{array}{l}\text { Radiographer-led } \\
\text { intravenous urography }\end{array}$ & 17 & 35.4 & 35.2 & - \\
\hline Mammography reporting & 14 & 29.2 & - & 10.5 \\
\hline Nuclear medicine reporting & 9 & 18.8 & - & 5.8 \\
\hline Paediatric reporting & 8 & 16.7 & - & 3.5 \\
\hline Chest reporting & 7 & 14.6 & - & 1.2 \\
\hline Conducting barium swallows & 7 & 14.6 & - & - \\
\hline Radiographer-led MRI & 6 & 12.5 & 18.5 & - \\
\hline Radiographer-led CT & 5 & 10.4 & - & - \\
\hline Counselling & 4 & 8.3 & - & - \\
\hline Patient referral & 4 & 8.3 & - & - \\
\hline Catheter insertion & 4 & 8.3 & - & - \\
\hline Conducting barium meals & 3 & 6.3 & - & - \\
\hline Radiographer-led referrals & 3 & 6.3 & - & - \\
\hline Supplementary prescribing & 1 & 2.1 & 12.0 & - \\
\hline
\end{tabular}

Source: IES and UH survey of imaging departments in the UK 
Table 2: Minimum and maximum lengths of training reported for extended role activities

\begin{tabular}{|c|c|c|c|}
\hline Activity & $\begin{array}{c}\mathbf{N} \\
\text { responses }\end{array}$ & $\begin{array}{c}\text { Minimum length of } \\
\text { training }\end{array}$ & $\begin{array}{c}\text { Maximum length of } \\
\text { training }\end{array}$ \\
\hline IV administration & 34 & less than a day & six months \\
\hline 'Red dot' & 22 & less than a day & six weeks \\
\hline Conducting $\mathrm{Ba}$ enemas & 21 & two days & two years \\
\hline Axial skeletal reporting & 16 & one year & two years \\
\hline $\begin{array}{l}\text { Appendicular skeletal } \\
\text { reporting }\end{array}$ & 19 & one year & two years \\
\hline Chest reporting & 6 & six months & two years \\
\hline Paediatric reporting & 5 & one year & 18 months \\
\hline Mammography reporting & 3 & six months & one year \\
\hline US reporting & 23 & six months & two years \\
\hline Ba enema reporting & 14 & one week & two years \\
\hline NM reporting & 3 & six months & two years \\
\hline Counselling & 2 & one day & three months \\
\hline Supplementary prescribing & - & - & - \\
\hline Patient referral & 3 & less than one day & - \\
\hline Catheter insertion & 2 & one day & six weeks \\
\hline Conducting Ba swallows & 1 & two years & - \\
\hline Conducting Ba meals & - & - & - \\
\hline Radiographer-led IVU & 6 & one day & two years \\
\hline Radiographer-led CT & 1 & two years & - \\
\hline Radiographer-led MRI & 2 & one year & two years \\
\hline
\end{tabular}

Source: IES and UH survey of imaging departments in the UK 
Table 3: The approval and accreditation of training for IV injections and Ba enemas

\begin{tabular}{lcccc} 
& \multicolumn{2}{c}{ IV training } & \multicolumn{2}{c}{ Ba enema training } \\
& Count & $\%$ & Count & $\%$ \\
\hline Not approved or accredited & 18 & 38.3 & 3 & 8.6 \\
Approved - body not stated & 6 & 12.8 & 6 & 17.1 \\
Approved by professional body & 2 & 4.3 & 2 & 5.7 \\
Approved by university & 5 & 10.6 & 7 & 20.0 \\
Accredited - body not stated & - & - & 5 & 14.3 \\
Accredited by professional body & 3 & 6.4 & 3 & 8.6 \\
Accredited by university & 3 & 6.4 & 2 & 5.7 \\
Approved and accredited - body not stated & 2 & 4.3 & 2 & 5.7 \\
Approved and accredited by professional & 5 & 10.6 & 2 & 5.7 \\
body & & & & \\
Approved and accredited by university & 3 & 6.4 & 3 & 8.6 \\
\hline Source: IES and UH survey of imaging departments in the UK & & & \\
\hline
\end{tabular}


Table 4: Proportion of trusts that had recruited applicants with unaccredited and accredited training

Unaccredited recruits accepted Accredited recruits accepted

\begin{tabular}{lcccc} 
& Count & $\%$ & Count & $\%$ \\
\hline No & 31 & 68.9 & 12 & 26.7 \\
Yes & 14 & 31.1 & 33 & 73.3 \\
Total & 45 & $100 \%$ & 45 & $100 \%$ \\
\hline
\end{tabular}

Source: IES and UH survey of imaging departments in the UK 
Table 5: Managers' confidence in previous accredited and unaccredited training received by recruits

\begin{tabular}{lcccc} 
& \multicolumn{2}{c}{$\begin{array}{c}\text { Ever lacked confidence in } \\
\text { unaccredited training? }\end{array}$} & \multicolumn{2}{c}{$\begin{array}{c}\text { Ever lacked confidence in } \\
\text { accredited training? }\end{array}$} \\
& Count & $\%$ & Count & $\%$ \\
\hline More than once & 8 & 22.9 & 1 & 2.5 \\
Just once & 2 & 5.7 & 0 & - \\
Never & 25 & 71.4 & 39 & 97.5 \\
Total & 35 & 100 & 40 & 100 \\
\hline
\end{tabular}

Source: IES and UH survey of imaging departments in the UK 